Article

\title{
Personal Autonomy in a Post-Secular Society
}

\author{
Raffaela Giovagnoli
}

Faculty of Philosophy, Pontifical Lateran University, Vatican City, 00120 Rome, Italy; giovagnoli@pul.it

Received: 17 August 2020; Accepted: 26 November 2020; Published: 3 December 2020

\begin{abstract}
The contemporary philosophical debate on autonomy shows several interesting perspectives that emphasize the role of social contexts for developing this human capacity. There is a shift from the classical notion of "moral" autonomy to the wider notion of "personal autonomy", and we underscore the "substantive view" that helps to provide arguments that support a plausible notion strictly connected with socialization and language use. In this article, we consider the source of autonomy that is represented by a communicative life-world in its ordinary and extra-ordinary dimensions to discuss the role of personal autonomy in a post-secular society. Moreover, we propose to adopt a pragmatic account to describe the social role of the autonomous agent in discursive contexts.
\end{abstract}

Keywords: moral autonomy; personal autonomy; life-world; post-secular society; social statuses; social attitudes

\section{Introduction}

In this work, we discuss the notion of autonomy by moving in a post-metaphysical pathway beyond the discussion on the possibility of free will, and we'll sketch the distinction between "moral autonomy" and "personal autonomy" [1]. Autonomy is classically represented by the thought of Kant, who maintains that we can ascribe moral autonomy to a person when she follows rules for willing and acting that derive from a universal law. Personal autonomy is a weaker notion that entails a reflection on the choice to follow a certain desire or the fact that individual identities are shaped by their values and social norms that are the basis for developing autonomy.

The distinction between autonomy and freedom must be emphasized. I. Berlin's perspective on "positive freedom" shows that autonomy means self-directed action, i.e., our will is not guided by external nature or other persons because we can plan our behavior and to act according to our goals and policies [2]. T. Green explores the notion of positive freedom in a Kantian sense: autonomy would be related to the human will and requires self-reflection and self-determination [3]. Freedom and autonomy ought to be distinguished for the role they have in human action. Therefore, if we think of freedom as a spontaneity of reflection, we have "practical spontaneity", which is characterized by self-determination, and "epistemic spontaneity", which refers to the laws of nature. Practical spontaneity does not exclude the fact that we can be influenced by the properties of the objects we perceive. Thus, autonomy requires that capacity of the will for self-determination, a capacity that realizes unconditionally, i.e., properties of the objects of volition are subjected to rational scrutiny to become reasons to act.

In the following article, we will sketch the debate on personal autonomy, which presents "procedural" and "substantive" perspectives. Some authors consider the procedural conditions of reflection, and others refer to normative factors of identity. Both differ from the classical Kantian account of autonomy as they emphasize not only the moral dimension. The "substantive" views, on the one side, solve the problem of the regression to basic desires in competition entailed by hierarchical models; and on the other side, they make individuals, relationships, and society compatible. Substantive perspectives point out the content of beliefs and preferences for autonomous choices. 
Finally, we'll describe the capacity for autonomy that is related to "decentralization" as a phenomenon that realizes in the process of socialization in our life-world characterized by perceptive and communicative features. For autonomy, we concentrate on a shared normative and linguistic competence that is necessary for the social life in a post-secular society.

\section{Moral Autonomy}

C. Korsgaard starts from the Kantian thought to highlight the distinction between "act" and "action" involving different senses of acting. We describe the act as a performance guided by a subjective goal like in means-end reasoning and gives rise to the so-called "heteronomous action". But these very acts can be subject to scrutiny under a universal principle to originate actions guided by the categorical imperative. We can say that actions distinguish human from animal behavior [4] because animal choices are directly influenced by external objects whose properties cause certain moves. Along the line of some Aristotelian ideas, Korsgaard distinguishes between merely voluntary actions and choices. Animal cognition is shaped by its own rationality based on processes of perception and adaptation. Differently, human beings can make moral choices, i.e., to classify actions into morally good and bad.

Moreover, we can distinguish between technical knowledge and moral knowledge. In his work Nicomachean Ethics, Aristotle points out the necessity of reflection for planning individual choices [5]. Moral consciousness is characterized by a peculiar reflection on the means to reach certain goals, which give rise to moral commitments. Consequently, we can underscore the role of "control" in human moral behavior, but must recall that the notion of control is discussed at different levels of "habitual" behavior.

Moral knowledge plays a fundamental role also for interpersonal relationships. In the infra-personal reflection, we experience the virtue of Phronesis, but in the inter-personal dimension we also need the virtue of Synesis. Synesis is an intentional modification of moral knowledge that comes into play when we morally evaluate the behavior of others. But, to do this, we need to grasp it, i.e., to be able to put ourselves in another context of action and morally acting accordingly. We need "empathy" that makes discernment of different perspectives and the tolerance resulting from it possible.

Korsgaard aims to demonstrate that autonomy requires a peculiar notion of reasoning relating to the "reflective self", which characterizes the figure of the "deep deliberator". Thomas Nagel overcomes normative internal processes of reflection because he gives weight to the external reasons moving our will, and this position is in contrast with Korsgaard's account [5]. Nagel refuses the Kantian account of the normative causality of the will because this kind of causality misconceives the distinction between merely following a rule and the application of the categorical imperative [6]. Korsgaard has a different "perspective from nowhere", because to reach a universal point of view, we need to have a normative conception of ourselves as persons. The normativity of the will favors the integrity and unity of moral behavior by making human beings capable of reaching a reflective distance on immediate impulses. Different from Nagel's perspective, moral reflection does not originate from reasons guiding our actions, and that could also guide our future choices ([5], pp. 227-228). Another interesting variation of the Kantian thought is represented by T. Hill's conception of deep deliberation [7]. Deep deliberation presents two fundamental features: (1) The role of "justifying reasons" and not "motivating reasons" for reflection as in Nagel's theory, and (2) the self-knowledge of the agent deriving from her own choices.

The debate on moral autonomy also includes the theories of "prudence" that take into account immediate pleasures, desires, that necessarily give the agent reasons to act because they shape her personality over time [8]. However, we can observe that deliberation, which presupposes the ability to influence future choices indirectly, requires the fundamental capacity to conceive make plans and resolutions useful for the future. This double process makes an agent responsible for her present choices that entail consequences for her future. The sense to be a deep deliberator resides in the capacity for critical reflection as values and inclinations may vary over time, so that cannot count as invariant presuppositions. 


\section{Authenticity and the Hierarchy of Desires}

Authenticity is a central notion in classical existentialist thought, and it is reinterpreted by several philosophers who think that autonomy requires a sort of self-knowledge based on a reflection on basic desires. In this sense, "self-authorship" (Raz) characterizes an "internalistic" view of autonomy as we ought to be, at least partly, the authors of our life shaped by present and past choices as well as the possible future actions we can think about. Personal autonomy is a wider notion than moral autonomy because it is oriented to self-realization. Some accounts of personal autonomy point out reflection on desires in competition, and we choose which of them could be the motor of our action. This process entails a hierarchy of desires-more precisely, we have basic desires and volitions that are the result of prior reflection. Gerald Dworkin and Harry Frankfurt proposed interesting theories based on authenticity under procedural conditions of reflection [9]. Self-determination is due to the undertaking of certain attitudes related to basic desires [10]. In this context, I. Berlin conceives autonomy (differently from liberty) as a sort of rational control: We can recall Odysseus, who limited his freedom to have the possibility of either being subjected to external stimuli or to the change to survive it ([9], pp. 14-15).

It is a peculiarity of human beings to choose to satisfy a prima facie desire or not. A person who forms the first-order desire to drink wine can also have the desire to not drink wine on the same level. Hierarchical theories of personal autonomy require, on the one side, "authenticity", namely, a higher-order reflection on concurrent desires that makes human behavior coherent. On the other side, they require willingness bound to the approval of a motive to act. This condition of "procedural independence" shows some critical points. The congruency of basic desires with individual rational will does not ensure autonomy as one be subject to submission [11]. The problem is that her basic desires could be the result of manipulation, even in the case of compatibility with her final choice after reflection.

Frankfurt proposes a variation of the model where we do not need to rationally approve the choice among basic desires. When we have desires in competitions, we perform a natural decision on a certain desire that will be evident in future action. According to Gary Watson [12], also this hierarchical model does not clarify the way in which the reflection on basic desires fosters autonomy because it could generate an infinite regression of desires. What is the normativity of process that isolates the desire which will be the motor of choice?

Moreover, the nature of higher-order attitudes is obscure if we do not clarify the normative nature of reflection on what we really want to pursue, by providing an "evaluation system". Michael Bratman proposes a variation of this "platonic challenge" that rests on the observation that agents usually choose among action attracting plans rather than desires in competition [13]. According to Bratman, rational evaluation could fail to recognize fundamental issues, so what is relevant for autonomy are cognitive attitudes that range over basic desires to form congruent life plans. Conative attitudes are constitutive of autonomy, namely, they have the authority to ground the agent's standpoint because they derive from a plausible planning process over time, so we can conclude that they are constitutive of personal identity. According to Bratman, we must move from the motivational to the "normative" content: The content of second-order attitudes is not desires, but "self-governing policies", i.e., motivationally effective in practical reasoning. The central point of his proposal is the introduction of a kind of "normative" content where the agents possess basic commitments, and among them, there exists a commitment to manage basic desires. In conclusion, self-management ought to be thought of as a part of their content so that commitments would acquire a higher-order that will include policy-like attitudes that provide the sense or motive to act given the presence of desires in competition.

The hierarchical models are overcome by those authors who consider the process along which a person develops autonomy to solve the problems entailed by the Frankfurtian notion of identification as "decisive endorsement". According to Christman, we must focus on the way in which a desire was formed, i.e., the conditions and factors that were relevant during the "process" of coming to have that value or desire. An autonomous person should show a lack of resistance in forming a certain desire, i.e., free from inhibitive constraints. It would be plausible to assume that we standardly can justify 
our choices and also describe processes and conditions of the acceptation of a desire and the steps of reasoning or the causal processes of that choice.

\section{Beyond the "Real Self View"}

Instead of considering the internal structure of reasoning, we can isolate properties external to the agent to grasp the relationship between individual agency and reasons. Wolf's argument is based on the fact that we can choose what reasons there are so that it becomes possible to overcome the "real self view" (RSV) entailed by the hierarchical model.

The RSV is exemplified by the Humean perspective, that Wolf describes as follow [14]:

Under normal conditions of freedom (i.e., in the absence of external constraints) an agent is able to govern her behavior on the basis of her will, which in turn can be governed by the set of the agent's desires.

On this view, it would be difficult to clearly distinguish between normally free actions and the ones that are intuitively unfree. In cases of hypnosis or kleptomania, we can observe that there are situations in which an agent may be constrained by her own desires and others in which she may feel forced to act from a will that, in one sense, but not in another, is not her own.

Frankfurt originally develops RSV by focusing on freedom based on the causation of our motivational system in standard cases, namely, whenever we are free from external constraints. Wolf proposes a different view about responsible agents; there are cases in which we question the responsibility of an agent even though we realize that she acted according to her real self. There are two fundamental senses to grasp the notion of responsibility. According to the first, we identify what can be called the "primary" causal agent of an event or fact (for instance, "the beautiful weather is responsible for the picnic's success"). But the causality of a rational agent entails judging the moral quality of her. However, RSV does not realize that autonomous agents are not only "authentic", as persons could be subject to different kinds of influences and constraints that make them not responsible for their behavior. In conclusion, autonomy requires control over behavior: Agents not only act "in" the world, but "on" the world. They can, in principle, reach that point of view detached from the world necessary for the attribution of deep responsibility.

Martin Fisher and John Ravizza introduce the requirement of "actual causal control" for morally responsible agents. For example, if a heroin addict is to be held morally responsible for doing heroin, she must be responsive to possible reasons not to do heroin. If she is not responsive, as such, she could not do otherwise, and thus, is not morally responsible for her drug use. A first fundamental condition for autonomy is the notion of "moderate reasons responsiveness". Moderate reasons responsiveness entails regular "reasons-receptivity" and at least weak "reasons-reactivity". "Reasons receptivity" allows the agent to recognize "the reasons that exist", and "reasons reactivity" allows the agent to translate reasons into choices and subsequent behavior. According to Fischer and Ravizza [15]:

the reactivity to reasons and receptivity to reasons that constitute the responsiveness relevant to moral responsibility are crucially asymmetric. Whereas, a very weak sort of reactivity is all that is required, a stronger sort of receptivity to reasons is necessary to this kind of responsiveness.

We consider a heroin user as morally responsible for her drug use when she is both regularly reasons-receptive to the reasons to not use heroin, and at least weakly-reactive to such reasons. This last case corresponds to the possible case where she could avoid taking drugs and could act for recognized right motives. (for instance, if she reflects on the fact that the last dose would be fatal). An autonomous agent needs to be only weakly reasons-reactive, but she must be regularly reasons-receptive. To evaluate a person's receptivity, we must observe that she recognizes sufficient reasons not only in one instance and that she follows a suitable pattern of reasoning. An autonomous person standardly recognizes how reasons fit together, and understands why one reason is stronger than another. And her pattern is normally understandable by a third party, so that can be considered as a defining characteristic of regular reasons-receptivity. 
We could provisionally conclude that a person can be recognized as autonomous whenever she is receptive to the right reasons, as determined by her moral community that represents the appropriate external observer. Autonomy would depend on substantive reasons internalized during the process of socialization; it has not only to do with responses and reactions to reasons, but also with the necessity to be exposed to several different perspectives to have the possibility of evaluating the possibility to act differently.

\section{The Substantive View}

An interesting challenge to the hierarchical model is represented by the Reason View, which characterizes the theory of Susan Wolf. Autonomy is related to self-reflection that confronts itself with objective reasons, i.e., reasons that are external to the pure exercise of practical reasoning. Therefore, considering the content of our beliefs and action seems fundamental for a performance to be autonomous.

Wolf also criticizes what she calls the "Autonomy View" as the view of metaphysical free will. Human beings are autonomous in a sense that entails responsibility for their actions. According to the Autonomy View, the ability necessary for responsibility is "bidirectional" - it is an ability to do one thing or another, an ability to do X or something other than X. On the contrary, according to Wolf's "Reason View", the ability necessary for responsibility is unidirectional-it is an ability to do one sort of thing, which is compatible with the inability to do anything else. This fundamental difference reflects itself on the sense of the flexibility of the agent's identity. For the Autonomy View a responsible agent is flexible as far as she is able to choose and act in a way that is not forced upon her by uncontrollable features or events of her past. However, the Reason View can better explain flexibility: Acting in accordance with Reason means to be sensitive and responsive to relevant changes in her situation and environment, naming to have the peculiar ability to choose and acting for the "right" reasons. Human beings have the intellectual power of recognizing the True and the Good that does not correspond to the metaphysical power of choosing and acting one path of action or another independently of any forces that could represent potential constraints. How can we grasp the nature of the power to act according to the True and the Good? First, we can observe that in the process of socialization, the agent is standardly taught to act justly and subsequently positively reinforced for doing so. Second, we recognize that it is right to act justly, and we can give reasons for this. Beyond the metaphysics of free will, these points show the compatibility between autonomy and socialization: One that can be determined by the Good and determined by the Past.

Freedom means not only to follow our own reasons, but rather to consider what Wolf calls "normative facts":

If inevitable features of myself — my gender, my race, my nationality, for example — and rationally arbitrary choices and twists of fate shaped my values and decisions, this does not seem to me to place objectionable limits on my status as a free and responsible agent. As long as these non-rational determinants do not prevent me from a sufficiently open-minded and clear-headed assessment of my values to allow me to see whether they fall into the range of the reasonable, and as long as my blindness to some other reasonable alternatives does not lead me to acts of intolerance or prejudice, then it seems that, for most intents and purposes, I am free and responsible enough. These non-rational determinants are, after all, what gives us our individuality and distinctiveness. If, at the limits, they can be in tension with our freedom and responsibility, in more central cases, they provide the basis for substantive identity and an attachment to the world without which no interest in freedom and responsibility could arise [14], p. 137.

Along the line of Wolf's "Reason View", we point out that autonomy also requires a consideration of "substantive" determinants of our identity and consequent choices (Stolijar, Benson, Oshana). For example, we can consider the choice of a college student, who is apparently autonomous as she may have chosen to internalize a value something like girls ought to look a certain way if they are to count as 
worthwhile to society. But, from this value arise actions that cannot be judged as autonomous because the value is oppressive in nature. Our criticism of procedural theories-also in historical variants-rests basically on the fact that they do not reflect upon the coercive normative facts that shape socialization. Differently, we can better understand cases in which agents can choose different alternatives if we consider the very content of the internalized norms that could diminish their autonomy.

Benson presents an interesting point to grasp the normative source of autonomy: The social and discursive dimension of "taking ownership" can explain how internalized invisibility (internalization of oppressive norms diminishing autonomy) would defeat the agent's capacity "to take ownership" of their actions [16]. By anticipating the consideration of a notion of autonomy that develops in discursive contexts, the active dimension of taking ownership requires that the agents can provide reasons for their actions and can respond to potential "challenges" starting from correspondent social contexts. Ownership plausibly grounds the social and discursive nature of autonomy. On the one side, it provides the agent the possibility of taking responsibility in a public context, and on the other side, it offers the possibility to speak for marginalized people.

\section{Autonomy, Life-World, and Post-Secular Society}

Taking ownership is an attitude acquired in the process of socialization. Habermas has shown how autonomy develops in virtue of communicative rationality that allows the agent to "decentralize" her egoistic situation and to recognize the conditions of an egalitarian dialog. We'll sketch the possibility of an autonomous agency to emphasize its role in the so-called "post-secular society" [17].

In the book Post-metaphysical Thinking II [18], Habermas describes the role of religion in our multicultural society beyond the sociological and philosophical debate running in the $80^{\prime}$ years about the process of secularization. This move means to overcome the narrow requirement that religion ought to express its voice in rational discourses by showing reasons that can be comprehended outside a restricted community. The peculiar expression "transcendence from within" is a key-notion to recognize the role of religion in private and public contexts. In Habermas thought, language is transcendental because it possesses the conditions under which we move in our natural and social worlds. And that allows us to express our own convictions. However, language can be understood in a wider sense to include "extra-ordinary" communication-and it is exactly this level of communication that reveals the potential of religion, and its role in human life.

Communicative rationality, which rests on procedural and formal conditions for rational discourses, must face the challenge of a fruitful confrontation with religion and theology [19]. Habermas himself has built his theory through reflections and dialogues with religious thought. In the ambit of Christian Theology, he takes into consideration some eminent authors who propose forms of cooperation in public discourses (for instance, Peukert and Schlüsser-Florenza). After the debate with J. Ratzinger, he recognizes the process of a "post-secularization" in which religious doctrines ought to be included in the public sphere in virtue of their motivational force.

After a new interpretation of the Husserlian notion of life-world, which takes into account ordinary language as the ground of human cognition, we must also consider the possibility of expressing the wide range of experiences we share. It represents human perceptive and cultural "background" that embeds all kinds of experiences and cultural products. We can investigate its structures by analyzing the process of communication, and in particular, the pragmatic attitudes we undertake using different kinds of speech acts. Life-world is constituted and renewed through communicative acts that allow us to accept, refuse, or challenge different kinds of validity claims depending on the reference to the natural or the social world. As a result, we can ground the possibility for autonomy on the background structure that characterizes learning processes by virtue of common reference to the objective world and social worlds, use of ordinary language with its peculiar structures, instrumental actions on the world, strategic actions in suitable contexts and communicative action required by strong forms of cooperation. 
This last point indicates an important distinction about the normative source of reasons for acting. We have two forms of normativity: The "weak normativity" of linguistic conventions and the "strong normativity" of traditions, values, and norms. Habermas introduced some reflections about the contemporary debate on "collective intentionality" [20], while referring to the Sellarsian metaphor of the "game of giving and asking for reasons". This option means that we move in a linguistic and social cognitive space that cannot be defined by psychological or neurological processes. Collective intentionality presupposes communication that embeds the normativity of traditions, roles, and institutions.

To move in a social "space of reasons" means to use symbols. Symbols do not only regulate our reference to external and social worlds in a cognitive sense [21]. They also possess the normativity that creates the "bounding effect" of traditions, roles, and institutions, as they are characterized by shared obligations and authorizations coordinating cooperation. The originality of the Habermasian latest reflection on communication resides in the analysis of the function of rituals, which seems to be the key-notion to comprehend several dimensions of cooperation (Habermas considers communication through the use of language, but also gestural communication). Rituals play not only the role of making individual motivations shareable, but also and of solving the classical sociological issue concerning the conflict between individual self-affirmation and collectivity. They show shared structures that are of epistemological relevance for researching human coordination. We can find the sense to conceive autonomy in a pragmatic sense based on coordination through communicative action: Agents share a common meaning derived by a normative background of theories, values, etc., so that they can transcend their "egocentric" perspective. This sort of "decentralization" is fundamental for cooperation and participation to the "rational discourses" that would ground plausible paradigms.

Habermas concentrates on extra-ordinary communication that he sees as embedded in rituals. But, if we look at social practices, in general, we can observe that rituals are the ground of individual behavior (in this case, they are simple habits) and of social behavior when we create and move in institutional contexts [22]. He investigates rituals to interpret religion as a fundamental source of social solidarity, values, and sense related to the communitarian cult ([18], chap. 2). Autonomy in a post-secular society entails undertaking a critical stance starting from a background that includes both religious and secular citizens in public and political arenas. Cristina Lafont raises an interesting criticism to Habermas because she maintains that we need a universal structure that makes reasons acceptable for everyone, beyond laic or religious perspectives [23]. Differently, Maeve Cook observes that we bring our contributions in public and political arenas necessarily moving from peculiar cultural perspectives [24].

However, we think that we ought to propose a notion of autonomy that, beyond the Rawlsian political notions of "justice" and "overlapping consensus", is worthy of being analyzed in terms of a plausible philosophy of language. Autonomous citizens can decentralize their own perspectives to have a fruitful confrontation with the other participants to public dialogues to avoid strong forms of relativism, as well as religious fanaticism. The reflection on autonomy is the basis to ground two main political questions: "Religious freedom" and the "principle of tolerance" ([18], chap. 9). Communicative rationality range over local communities or subcultures to avoid limitations on their freedom so that they can recognize each other as active parts of a common political community and preserve at the same time their cultural identity. The application of the principle of tolerance rests on the inclusive and deliberative procedures of a democratic formation of the will. In this context, we can distinguish between two different attitudes toward religion. We can assume a "laic" attitude that is neutral about religious beliefs or a "laicistic" one that is actively opposed to them. However, it ought to be possible to bring different beliefs into a public discussion by making their content accessible to general comprehension.

After the process of "rationalization" in western society that has been at the center of the brilliant work of Max Weber, Habermas recognizes the role of religion to give sense to life and to propose positive values for contrasting the political and economic power of capitalism. Concerning some 
contemporary esoteric tendencies, which Habermas label as a symptom of ego weakness and regression, something like an impossible return to mythical forms of thought, he recognizes a "genuine" discourse that is worthy of being highlighted:

Reading Aquinas' Summa Contra Gentiles, I am struck by the complexity and sheer degree of differentiation-the gravity and the stringency of a dialogically constructed argument. I am an admirer of Aquinas. He represents a form of spirit that is able to ground its authenticity from out of its own resources. It is also simply a fact that there is no longer this kind of firmament in the morass of contemporary religiosity. In a homogenizing media society, everything loses its gravity, perhaps even institutionalized Christianity itself [25].

Substantive theories of personal autonomy rest on the importance of social norms for individual choices, and there are several authors who are discussing the topic in social epistemology (Hardwig, Welbourne, Schmitt, Baier, Webb, Goldman, Jones, Fricker Faulkner, Lipton, Kusch, Lackey). They observe that community is fundamental for knowledge and autonomy [26]. In this sense, epistemic agents mostly rest on testimonial transmission for their knowledge, and there exists a wide range of information together with a division of epistemic labor (Putnam, Kitcher).

A plausible notion of personal autonomy ought to be grounded on the participation in a practice in which we recognize reasons for knowing and acting as reasons that are publicly recognized because of the nature of their content. We can inherit them by transmission, or we can be able to know the implicit commitments and entitlements that structure their content. To clarify this theoretical option, we could adopt the Brandomian "scorekeeping model" $[27,28]$ to grasp the know-how implied by the "social role" of an individual as the "scorekeeper" moving in the "game of giving and asking for reasons". In particular, an autonomous agent would be able to attribute and undertake commitments and entitlements through which the recognition of "deontic statuses" (commitments and entitlements) obtains. The model is further described in the book Between Saying and Doing [29], where Brandom shows the functioning of human discursive practices, which differ from practices based on reliable dispositions to respond to environmental stimuli we observe in non-human beings. These practices are typical of human beings because they reside in peculiar inferences, due to the use of our ordinary language. The combinatory resources provided by language use gives rise to a particular cognitive skill, namely, the capacity to "ignore" factors that are not relevant for fruitful inferences. The social role of a "scorekeeper" makes agents able to justify and to take responsibility for their assertions (or the assertions of others). In my opinion autonomy requires an explanation of critical reflection bound to an intersubjective discursive practice that favors a process of reciprocal comprehension among different forms of life.

A fundamental condition for autonomy is, therefore, the internalization of the normative structure of "dialogical" rationality. Here we are moving at the normative level of communication, i.e., the level we consider as sufficient for autonomous agency. A self-transparent process of identification of shared commitments is not required for autonomy. We can think at the process of justification of reasons through different sources: (1) By giving reasons for it, or (2) by referring to the authority of another agent, or (3) by demonstrating the capacity of the agent reliably to respond to environmental stimuli. The participation in the social space of reasons makes the agents capable of mastering the communicative structure of justification by "default" and "challenge". We move from the "semantic" sense that shows the inferential commitments (governed by material incompatibility) the agents must acknowledge and from the "pragmatic" sense that reveals the normative structure of that acknowledgment as a social net of deontic attitudes.

\section{Conclusions}

In this article, we have briefly described the contemporary debate on personal autonomy and provided arguments to support a substantive view to underscore the role of social contexts for the development of autonomy. Social norms could diminish autonomy in case they are discovered to be interiorized without any sort of control or ownership. However, this control does not rise from 
individual self-reflection as described in the procedural theories. Rather, it requires active participation in social spaces where persons master their communicative competence that becomes fundamental in the social world of norms, institutions, and religious views. This communicative competence is compatible with the pragmatic account proposed by Brandom. On the one side, we can consider ourselves as agents that are capable of recognizing the material inferential commitments embedded in our claims. On the other side, the deontic attitudes of the undertaking and attributing commitments represent the pragmatic dimension that structures our participation in fruitful and open dialogues where we are exposed to different reasons, and we can accept, challenge or refuse validity claims.

Funding: This research received no external funding.

Acknowledgments: I warmly thank Lorenzo Magnani for the thoughtful comments, Bob Brandom and Marina Oshana for the discussion on the plausibility of a social account of autonomy and the reviewers for their careful work.

Conflicts of Interest: The author declares no conflict of interest.

\section{References}

1. Johnston, D. The Idea of Liberal Theory; Princeton University Press: New York, NY, USA, 1994.

2. Waldron, J. Moral and Personal Autonomy. In Autonomy and the Challenges to Liberalism; Christman, J., Anderson, J., Eds.; Cambridge University Press: New York, NY, USA, 2005.

3. Berlin, I. Two Concepts of Liberty. In Four Essays on Liberty; Oxford University Press: Oxford, UK, 1969; p. 131.

4. Green, T.H. On the Different Senses of Freedom. In In Lectures on the Principles of Political Obligation; Green, T.H., Ed.; Cambridge University Press: London, UK, 1941.

5. Korsgaard, C. The Sources of Normativity; Cambridge University Press: Cambridge, MA, USA, 1996.

6. Nagel, T. Universality and the reflective self. In The Sources of Normativity; Korsgaard, C., Ed.; Cambridge University Press: Cambridge, MA, USA, 1996; p. 201.

7. Hill, T. W Autonomy and Self-Respect; Cambridge University Press: New York, NY, USA, 1991.

8. Duque, F. Liberdad y sacrificio: Deber ser para dejar ser. Rev. Port. Filos. 2005, 61, 667-686.

9. Dworkin, G. The Theory and Practice of Autonomy; Cambridge University Press: Cambridge, MA, USA, 1988.

10. Frankfurt, H. The Importance of What We Care About; Cambridge University Press: Cambridge, MA, USA, 1988.

11. Christman, J. Autonomy and Personal History. Can. J. Philos. 1991, 21, 1-24. [CrossRef]

12. Watson, G. Free Agency. J. Philos. 1975, 72, 205-220. [CrossRef]

13. Bratman, M. Planning Agency, Autonomous Agency. In Autonomy and the Challenges to Liberalism; Christman, J., Anderson, J., Eds.; Cambridge University Press: Cambridge, UK, 2005; pp. 33-57.

14. Wolf, S. Freedom within Reason; Oxford University Press: New York, NY, USA, 1990; p. 28.

15. Fisher, M.J.; Ravizza, S.J. Responsibility and Control; Cambridge University Press: Cambridge, UK, 1998; p. 69.

16. Benson, P. Taking Ownership: Autonomy and Voice in Autonomous Agency. In Autonomy and the Challenges to Liberalism; Christman, J., Anderson, J., Eds.; Cambridge University Press: Cambridge, UK, 2005; pp. 118-119.

17. Casanova, J. Exploring the Postsecular: Three Meanings of "the Secular" and their Possible Transcendence. In Habermas and Religion; Calhoun, C., Mendieta, E., VanAntwerpen, J., Eds.; Polity Press: Cambridge, UK, 2013; pp. 27-48.

18. Habermas, J. Post-metaphysical Thinking, Philosophical Essays; MIT Press: Cambridge, MA, USA, 1992.

19. Arens, E. Habermas und die Theologie; Patmos: Dusseldorf, Germany, 1989.

20. Habermas, J. Between Naturalism and Religion; Cambridge Polity: Cambridge, MA, USA, 2008.

21. Magnani, L. Abductive Cognition; Springer: Cham, Switzerland, 2009.

22. Giovagnoli, R. From Habits to We-intentionality. Rituals as Social Habits. In The Logic of Social Practices; Giovagnoli, R., Lowe, R., Eds.; Springer: Cham, Switzerland, 2020.

23. Lafont, C. Religion and the Public Sphere: What are the Deliberative Obligation of Democratic Citizenship? In Habermas and Religion; Calhoun, C., Mendieta, E., VanAntwerpen, J., Eds.; Polity Press: Cambridge, MA, USA, 2013; pp. 230-248.

24. Cooke, M. Violating Neutrality? Validity Claims and Democratic Legitimacy. In Habermas and Religion; Calhoun, C., Mendieta, E., VanAntwerpen, J., Eds.; Polity Press: Cambridge, MA, USA, 2013; pp. 249-276.

25. Habermas, J. Religion and Rationality; Cambridge Polity: Cambridge, MA, USA, 2002; p. 152. 
26. Giovagnoli, R. Autonomy as a Social Role and the Function of Diversity. Philosophies 2018, 3, 21. [CrossRef]

27. Brandom, R. Making It Explicit; Cambridge University Press: Cambridge, MA, USA, 1994.

28. Giovagnoli, R. Autonomy. A Matter of Content; FUP: Firenze, Italy, 2007.

29. Brandom, R. Between Saying E Doing; Oxford University Press: Oxford, MS, USA, 2010.

Publisher's Note: MDPI stays neutral with regard to jurisdictional claims in published maps and institutional affiliations.

(C) 2020 by the author. Licensee MDPI, Basel, Switzerland. This article is an open access article distributed under the terms and conditions of the Creative Commons Attribution (CC BY) license (http://creativecommons.org/licenses/by/4.0/). 